\title{
Methods of registrar post allocation
}

\author{
Paul Ramchandani, Kapil Sayal and Navneet Kapur
}

\begin{abstract}
Little is known about how posts are allocated to enable Individuals to experience a comprehensive premembership psychiatric training. A questionnaire survey of 26 teaching hospltal training schemes was carried out. This concentrated on registrar training post-Part 1 MRCPsych (now known as senior house officers since the Calman changes). Four main methods of allocation, with varying degrees of trainee involvement, were identfiled. The amount of prior notice given of the trainees' next placement and percelved advantages and disadvantages were compared between the four methods. Implications for practice are discussed.
\end{abstract}

The process of general psychiatric training is under increasing scrutiny with the introduction of Calman changes (Calman, 1993) and the Royal College of Psychiatrists initiative on personal training files (1996). Less attention has been paid to how this training is "put together', that is how individual posts within a scheme are allocated to ensure a comprehensive psychiatric apprenticeship. In contrast to many other medical specialities psychiatric registrar training schemes tend not to have fixed rotations, and posts are traditionally allocated every six months. There are a variety of ways in which this is done (McClintock, 1993).

Allocation of posts is important because it has a direct impact on the quality and variety of training received. In our experience it is also a significant source of anxiety for psychiatric trainees. Two factors of particular concern are the degree to which trainees are able to determine future placements and the amount of prior notice they are given of those placements.

\section{The study}

A nine-item semi-structured questionnaire was designed to obtain details of how posts are allocated on psychiatry training schemes. Details were sought of perceived advantages and disadvantages of the system used and the practicalities of administering it. The questionnaires were sent to the 26 clinical tutors of all the teaching hospital psychiatry registrar training schemes in England, Scotland and Wales. A reminder letter and further copy of the questionnaire were sent to non-responders after eight weeks.

\section{Findings}

Twenty-five questionnaires were returned. This gave a response rate of $96 \%$.

\section{Different methods of allocation}

In all schemes trainees had some degree of involvement in the allocation of their next post to the extent of being able to express a preference (usually by listing three choices and/or meeting with clinical tutors). This served as a guide for eventual allocations.

After trainees had expressed their preferences, there were four main methods of post allocation. These are listed in Table 1 together with the number of rotational training schemes using each method. The amount of trainee involvement in their final post allocation varied. The most common method (and the one with least trainee input) involved the clinical tutor deciding on the allocations for the trainees. The second method had further trainee involvement. in the form of trainee representatives being present at the final tutors allocation meeting. The third method involved a meeting of all trainees together with the tutor to negotiate final allocations based on a draft drawn up by the tutor. The fourth method involved the trainees deciding their next allocation between themselves.

\section{Advantages and disadvantages of each method}

The main advantages and disadvantages expressed by the tutors are summarised in Table 1. Regardless of the allocation method used the tutors felt that they allowed trainees to have some input in terms of expressing a choice, and that they were flexdble in meeting training, clinical and academic needs. Difficulty in filling unpopular posts was identified as a common problem which restricted this flexdbility. 
TRAINEES' FORUM

Table 1. Allocation methods

\begin{tabular}{|c|c|c|}
\hline Melhod & $\begin{array}{l}\text { Number of rotational } \\
\text { training schemes (\%) }\end{array}$ & \\
\hline \multirow[t]{8}{*}{ Tutor decides } & $14(56)$ & Advantages \\
\hline & & $\begin{array}{l}\text { Pivate personal circumstances can be considered } \\
\text { confidentially }\end{array}$ \\
\hline & & Avoids arguments between trainees \\
\hline & & $\begin{array}{l}\text { Bargains/promises can be made for next round of job } \\
\text { allocation }\end{array}$ \\
\hline & & Disadvantages \\
\hline & & Trainee disappointment May feel tutors 'unfair' \\
\hline & & Clinical tutor workload \\
\hline & & Lack of trainee involvement \\
\hline \multirow{6}{*}{$\begin{array}{l}\text { Tutor decides with trainee } \\
\text { representatives present }\end{array}$} & $5(20)$ & Advantages \\
\hline & & Fairness - seen to be no favouritism \\
\hline & & $\begin{array}{l}\text { Avoids 'personality clashes' between tutors and } \\
\text { traineөs }\end{array}$ \\
\hline & & Disadvantages \\
\hline & & Complex and lengthy process \\
\hline & & Some posts are never chosen \\
\hline \multirow{7}{*}{$\begin{array}{l}\text { Tutor produces draft then } \\
\text { trainees negotiate }\end{array}$} & $5(20)$ & Advantages \\
\hline & & $\begin{array}{l}\text { All parties are involved and share responsibility for } \\
\text { outcome }\end{array}$ \\
\hline & & Equity. Open discussion of reasons for decision-making \\
\hline & & Allows flexibility and compromise \\
\hline & & Disadvantages \\
\hline & & $\begin{array}{l}\text { Tutor has to act as moderator to ensure 'stronger' } \\
\text { personalities do not dominate }\end{array}$ \\
\hline & & Some posts oversubscribed, so disappointed traineөs \\
\hline \multirow[t]{5}{*}{ Traineөs decide } & 1 (4) & Advantages \\
\hline & & Trainees have control over career path \\
\hline & & Learn negotiation skills \\
\hline & & Disadvantages \\
\hline & & Negotation can be difficult and unconstructive \\
\hline
\end{tabular}

How far in advance do trainees know of their next post

There was a large variation in the notice trainees received of their next post. This ranged from two to three weeks in one scheme to another where trainees knew their next three posts (covering 18 months of training) within two months of joining the rotation. Systems where the tutor decided allocations alone tended to give trainees less notice of their next post (average six weeks) compared to those with greater trainee involvement (average 10 weeks).
How long have these systems been running/ future plans

The schemes had been running these systems for between two and 20 years. The schemes where tutors allocated posts tended to have been running in this way for longer without recent change. Fifteen of the tutors were considering, or had recently considered, making changes to the system of post allocation. Six were considering a set rotation whereby posts would be linked in some way. One training scheme was planning to implement such a system. This was felt to have 
the advantage of giving trainees the chance to plan their training better, knowing further in advance what their posts would be. The main disadvantage was felt to be a lack of flexibility.

\section{Scheme size}

Information on size was obtained for 16 of the schemes. They ranged from 12 to 53 trainees. There was no effect of scheme size on method of post allocation, with large schemes using each of the four methods described.

\section{Other considerations}

Several of the tutors mentioned the difficulties which reduced levels of recruitment were causing (Storer, 1996). It was felt to lead to increasing conflict between training needs and manpower requirements (particularly the need to fill general adult and old age psychiatry posts).

\section{Comment}

The present study has highlighted the stages involved in post allocation, and the inherent difficulties this involves. The high response rate means it strongly reflects current practice (at least in larger training schemes). It is restricted to teaching hospital schemes, which may not be representative of all training schemes. It is a study of tutor's rather than trainees' views.

All the schemes surveyed allow trainee preferences to be taken into account, however, this varies widely in degree. Greater trainee involvement allows them more control of their training. particularly in terms of planning of future careers and for examination purposes (for example ensuring that a number of sub-speciality posts are covered, working in 'quieter' posts at the time of examinations).

Of particular concern is the large variation of notice which trainees are given of their next post. The period of uncertainty before a final decision is made can be a considerable source of stress, especially in schemes covering large geographical areas where some posts result in personal upheaval. The argument frequently used against systems which allow more notice is that flexibility is necessary where success in MRCPsych exams can mean several people leaving a scheme at one time. In this situation there may be a conflict between training needs and service requirements.

The College provides no specific guidelines and there is no standardised procedure by which post allocation occurs. Most other clinical specialities use fixed rotations and this allows for a greater degree of certainty and planning in training. While the traditional method of post allocation in psychiatry retains some flexibility it is questionable whether something as important as general professional training should be planned on a six monthly basis.

One of the training schemes surveyed has overcome these problems to a large extent by allowing trainees to choose their three remaining registrar posts soon after joining the scheme. This allows considerable advance knowledge of changes of location. Some flexibility is still retained as posts can be switched later should personal circumstances or career intentions change.

\section{Acknowledgements}

We thank Dr Bob Fieldsend and Dr Vicky Webb for their helpful comments on the text.

\section{References}

Calman, K. C. (1993) Hospital Doctors: Training for the Future. Report of the Working Group on Specialist Medical Training. London: HMSO.

MCCLINTOCK, T. (1993) Allocation of posts within a registrar scheme. Psychiatric Bulletin, 17, 563-564.

ROYAL COLlEgE OF PSYCHIATRISTS (1996) Log Books or Personal Training Flles-A College Working Party. Psychiatric Bulletin, 20, 57-58.

STORER, D. (1996) Recruitment into psychiatry. Psychiatric Bulletin, 20, 177-178

*Paul Ramchandani, Registrar in Psychiatry. The Park Hospital, Headington, Oxford OX3 7LQ; Kapil Sayal, Registrar in Psychiatry, Maudsley/ Bethlem Hospitals; and Navneet Kapur, Registrar in Psychiatry, Leeds General Infirmary

*Correspondence 